\title{
Plantio adensado não controla a sigatoka-negra da bananeira
}

\author{
Luadir GASPAROTTO¹, José Clério R. PEREIRA¹, Sônia Maria F. ALBERTINO², Mirza Carla N. PEREIRA \\ RESUMO \\ Algumas publicações relatam que o adensamento populacional dos bananais reduz a severidade da sigatoka-negra (Mycosphaerella \\ fijiensis). Instalou-se um ensaio com cinco tratamentos e quatro repetições. Os tratamentos 1.600, 2.000, 2.400, 2.800 e 3.200 \\ plantas.ha-1 da cultivar D'Angola foram instalados em parcelas agrupadas de $2.000 \mathrm{~m}^{2}$ cada. O tamanho das parcelas foi fixo e o \\ número de plantas por parcela variou conforme o espaçamento adotado para cada população. A área de $2.000 \mathrm{~m}^{2}$ foi dividida \\ em quatro subáreas de $500 \mathrm{~m}^{2}$, considerando-as como parcelas. Em cada subárea selecionaram-se 15 plantas centrais para serem \\ avaliadas. $\mathrm{Na}$ época do florescimento registraram-se a severidade da doença na folha $\mathrm{n} .{ }^{\circ} 10$ e o número de folhas viáveis. $\mathrm{Na}$ \\ colheita, a altura e o diâmetro do pseudocaule e o peso dos cachos, das pencas e dos frutos. A análise conjunta dos dados indica \\ que todos os tratamentos foram semelhantes entre si e que o adensamento das plantas não controlou a sigatoka-negra.
}

PALAVRAS-CHAVE: Mycosphaerella fijiensis, Plátano, Controle cultural.

\section{Dense plantation do not control banana black-sigatoka}

\begin{abstract}
Many publications show that plantations of high density of bananas decrease the severity of black-sigatoka (Mycosphaerella fijiensis). To test this hypothesis it was instaled an experiment with five treatments and four repetitions. The treatments were density plant of 1.600, 2.000, 2.400, 2.800 e 3.200 plant.ha $^{-1}$. The cultivar planted was D'Angola and each plot had fixed $2.000 \mathrm{~m}^{2}$, the number of plants in each plot changed in accordance with the treatment tested. The plots were divided in four subplots of $500 \mathrm{~m}^{2}$ where 15 plants located in the center were measured. The evaluation of severity was carried out in the leaf number ten during the flowering period. It was also evaluated the numbers of viable leaves, height, diameter and weight of production (banch, bunches and fruits). The analyses did not show effect of high density in the parameter measured and it was conclued that the treatments tested had not control black-sigatoka.
\end{abstract}

KEYWORDS: Mycosphaerella fijiensis, platano, cultural control.

1 Embrapa Amazônia Ocidental - Rodovia AM - 10, Km 29. Caixa Postal 319, CEP 69048-660. Manaus - AM - Brasil. e-mail: gasparotto@cpaa.embrapa.br

2 Bolsista da Fundação de Amparo à Pesquisa do Estado do Amazonas - FAPEAM - Rua Recife, 320 - Parque 10 CEP. 69057-002. Manaus - AM - Brasil. e-mail: sonialbertino@ufam.edu.br 


\section{INTRODUÇÃO}

A bananicultura apresenta grande importância econômica e social para o estado do Amazonas. Apesar disso, a produção estadual só atende cerca de $50 \%$ da demanda interna. A partir de 1998, com a constatação da sigatoka-negra (Mycosphaerella fijiensis) a produção esta reduzida drasticamente, pois a doença causa $100 \%$ de perdas na produção das cultivares Maçãa, Prata Comum e D'Angola, tradicionalmente plantadas na região.

No Brasil a doença foi constatada em fevereiro de 1998 nos municípios de Tabatinga e Benjamin Constant no estado do Amazonas, fronteira do Brasil com a Colômbia e Peru (Pereira et al., 1998). Atualmente, encontra-se disseminada nos Estados do Amazonas, Pará, Roraima, Amapá, Acre, Rondônia, Mato Grosso, Mato Grosso do Sul, São Paulo, Paraná, Minas Gerais, Santa Catarina e Rio Grande do Sul (Gasparotto et al., 2006).

Para viabilizar o plantio das cultivares tradicionalmente aceitas pela população local, novas tecnologias devem ser investigadas, como o plantio adensado. Alguns pesquisadores (Stover, 1987; Belalcazar et al., 1991; Perez, 1993; Vargas, 1993) recomendam o plantio de plátanos em estande adensado para reduzir a severidade da sigatoka-negra, explorando-as comercialmente por apenas um ciclo anual, como forma de viabilizar a sua produção, principalmente para atender a demanda das populaçôes mais carentes.

Neste trabalho, avaliou-se o efeito do plantio adensado do plátano cultivar D’Angola na redução de severidade de sigatoka-negra e na sua produção.

\section{MATERIAL E MÉTODOS}

$\mathrm{O}$ ensaio foi desenvolvido na área experimental da Embrapa Amazônia Ocidental no período de janeiro de 2004 a abril de 2005, durante um ciclo da cultura. Na cova de plantio foram colocados $400 \mathrm{~g}$ de calcário dolomítico, $5 \mathrm{l}$ de esterco de galinha, $50 \mathrm{~g}$ de FTE-BR12 e $240 \mathrm{~g}$ de superfosfato simples e em cobertura no $2^{\circ}, 4^{\circ}, 7^{\circ}$ e $9^{\circ}$ mês após o plantio foram distribuídos a lanço $132 \mathrm{~g}$ de sulfato de amônio e $270 \mathrm{~g}$ de cloreto de potássio por planta por aplicação. Os tratamentos consistiram do plantio de 1.600, 2.000, 2.400, 2.800 e 3.200 plantas.ha ${ }^{-1}$ da cultivar D'Angola, distribuídas em parcelas agrupadas de $2.000 \mathrm{~m}^{2}$ cada. O tamanho das parcelas foi fixo e o número de plantas por parcela variou conforme o espaçamento adotado para cada população. A área de 2.000 $\mathrm{m}^{2}$ foi dividida em quatro subáreas de $500 \mathrm{~m}^{2}$, considerando-as como parcelas. Em cada subárea selecionaram-se 15 plantas centrais para serem avaliadas. $\mathrm{Na}$ época do florescimento, foi avaliado o número de folhas viáveis por planta e a severidade da doença na folha número 10 . Na avaliação da severidade foi utilizada a escala de Stover, modificada por Gauhl (Orozco-Santos, 1998), onde: $1=$ folhas sem sintomas da doença e aquelas com até 10 manchas; $2=$ folhas com área foliar lesionada $<5 \%$; 3 = folhas com $6-15 \%$ de área foliar lesionada; 4 = folhas com $16-33 \%$ de área foliar lesionada; 5 = folhas com $34-50 \%$ de área foliar lesionada; $6=$ folhas com área foliar lesionada $>50 \%$. Considerou-se como viável as folhas sadias e as que apresentavam no dia da avaliação até a nota 3 da escala de Stover. Na colheita, foram avaliadas a altura e o diâmetro do pseudocaule das plantas e o peso dos cachos, das pencas e dos frutos. Os dados foram submetidos à análise de variância.

\section{RESULTADOS E DISCUSSÃO}

Os resultados obtidos encontram-se na Tabela 1. Em todos os tratamentos, o número de folhas viáveis por planta, a severidade de sigatoka-negra na folha número 10 , os dados fitotécnicos e os de produção não apresentaram diferenças significativas entre si. O número de folhas viáveis no florescimento foi inferior a nove e a severidade da doença na folha 10 foi superior a $30 \%$. Na colheita, os cachos atingiram cerca de 6 a $8 \mathrm{~kg}$ com frutos pouco desenvolvidos e número reduzido por cacho devido ao ataque do patógeno. Cerca de 50 dias após a emissão do cacho as plantas encontravam-se com todas as folhas mortas devido ao ataque da sigatoka-negra.

Trabalhando com estandes de 2000, 2500, 3000 e 3500 plantas de plátanos.ha ${ }^{-1}$ no Equador (Espinoza, 2003), Nicarágua (Vargas \& Castillo, 2003), Venezuela (Surga et al., 2003), República Dominicana (Céspedes \& Suárez, 2003) e Panamá (Marcelino et al., 2003), os pesquisadores constataram que a severidade da sigatoka-negra foi semelhante em todos estandes, culminando com maior produtividade nos estandes mais populosos, porém com cachos e frutos menores. Vicente (1998) também relata que, em Cuba, a severidade da sigatoka-negra foi alta independente da população de plantas nos estandes.

Daub \&Ehrenshalf (2000) relatam que a atividade da cercosporina, toxina não específica envolvida na patogênese, é reduzida quando ocorre diminuição da luminosidade, pois depende da fotosensibilização para atuar. Nos plantios adensados de plátanos a diminuição da luminosidade que incide no interior do dossel das plantas provavelmente não é suficiente para reduzir a patogênese do fungo, a um nível que possa controlar economicamente a sigatoka-negra, conforme sugerido por Belalcazar et al. (1991). Os fungos fitopatogênicos pertencentes ao gênero Cercospora, de um modo geral causam doenças em folhas inferiores. Nessa situação, a redução da luminosidade pode retardar a patogênese e conseqüentemente a severidade da doença. Com relação a $M$. fijiensis, o fungo causa alta intensidade de infecçôes nas folhas vela, um, dois e três. Nos plátanos, as folhas com cerca de 35 a 40 dias de idade que são atacadas pela sigatoka-negra estão praticamente destruídas e as plantas não conseguem manter mais que seis a 


\begin{tabular}{|c|c|c|c|c|c|c|c|c|c|}
\hline $\begin{array}{l}\text { Tratamentos } \\
\left.\text { (Plantas.ha- }^{-1}\right)\end{array}$ & $\mathrm{NFV}^{*}, 1$ & SEV10** & $\begin{array}{l}\text { Altura das } \\
\text { plantas (m) }\end{array}$ & $\begin{array}{l}\text { Diâmeto do } \\
\text { pseudocaule } \\
\text { (cm) }\end{array}$ & $\begin{array}{l}\text { Peso do } \\
\text { cacho }(\mathrm{kg})\end{array}$ & $\begin{array}{l}N^{\circ} \text { de pencas/ } \\
\text { cacho }\end{array}$ & $\begin{array}{l}\text { Peso das } \\
\text { pencas }(\mathrm{kg})\end{array}$ & $\begin{array}{l}\mathrm{N}^{\circ} \text { de frutos/ } \\
\text { cacho }\end{array}$ & $\begin{array}{l}\text { Peso do } \\
\text { fruto(g) }\end{array}$ \\
\hline 1600 & 8,72 & 30,85 & 3,42 & 16,2 & 7,88 & 5,3 & 1,48 & 27,5 & 286,4 \\
\hline 2000 & 8,25 & 48,30 & 3,20 & 15,5 & 6,98 & 5,5 & 1,30 & 28,2 & 247,8 \\
\hline 2400 & 8,82 & 30,00 & 3,42 & 16,2 & 7,60 & 5,3 & 1,43 & 29,2 & 277,8 \\
\hline 2800 & 7,92 & 52,12 & 3,22 & 15,9 & 8,22 & 5,8 & 1,45 & 28,9 & 285,3 \\
\hline 3200 & 8,85 & 41,50 & 3,12 & 14,8 & 8,00 & 5,7 & 1,43 & 26,1 & 305,9 \\
\hline$\hat{\mathrm{Y}}$ & 8,55 & 25,48 & 3,62 & 17,16 & 6,85 & 4,86 & 1,39 & 29,21 & 234,74 \\
\hline CV(\%) & 3,97 & 19,02 & 2,83 & 1,85 & 11,74 & 4,42 & 12,00 & 5,05 & 9,93 \\
\hline
\end{tabular}

${ }^{*}$ NFV - Número de folhas viáveis: **SEV10 - Percentagem de área foliar lesionada na folha número 10. ${ }^{1}$ As médias das variáveis analisadas não apresentam diferenças significativas entre si pelo teste $\mathrm{F}$ a $5 \%$ de probabilidade.

sete folhas viáveis. Nessas circunstâncias, mesmo adensando o plantio, não ocorre auto-sombreamento das folhas; portanto a severidade da sigatoka-negra não é reduzida.

$\mathrm{Na}$ realidade, o plantio de plátanos em estande adensado, cuja exploração é por apenas um ciclo, não é uma prática cultural para controlar a sigatoka-negra, mas para aumentar a produtividade do bananal uma vez que no primeiro ciclo as perdas, causadas pela doença, nos plátanos giram em torno de 50 a $60 \%$ a produção.

\section{CONCLUSÃO}

O plantio adensado do cultivar D'Angola, até a densidade de 3.200 plantas.ha ${ }^{-1}$, nas condições da Amazônia Ocidental, não reduz a severidade da sigatoka-negra.

\section{AGRADECIMENTOS}

Os autores agradecem à Fundação de Amparo à Pesquisa do Estado do Amazonas (FAPEAM) pela concessão da bolsa à terceira autora e pelos recursos financeiros para execução do trabalho.

\section{BIBLIOGRAFIA CITADA}

Belalcazar, C.; Toro-Meza, J. C.; Jaramillo-Celis, R. 1991. El cultivo del plátano en el trópico. Armenia (Colômbia), Feriva. 376pp.

Céspedes, C.; Suárez, P. 2003. Evaluación de sistema de cultivos de plátanos en alta densidad, con un manejo integrado de la sigatoka negra, promoviendo o uso racional de los fungicidas. In: Pocasangre, L.; Rosales, F.E.; Guzmán, M. (Eds.). Capacitacion e investigación para el manejo integrado de la sigatoka-negra del plátano en America Latina y el Caribe. Documento II. Informe final. San Jose, INIBAP. p.228-241.
Daub, M.E.; Ehrenshaft, M. 2000. The photoactivated Cercospora toxin cercosporin: contributions to plant disease and fundamental biology. Annual Review Phytopathology, 38: 461- 490.

Espinoza, A. 2003. Evaluacción de sistema de cultivos de plátanos en alta densidad, con un manejo integrado de la sigatoka-negra, promoviendo o uso racional de los fungicidas. In: Pocasangre, L.; Rosales, F. E.; Guzmán, M. (Eds.). Capacitacion e investigación para el manejo integrado de la sigatoka-negra del plátano en America Latina y el Caribe. Documento II. Informe final. San Jose, INIBAP. p.96-109.

Gasparotto, L.; Pereira, J.C.R.; Hanada, R.E.; Montarroyos, A.V.V. 2006. Sigatoka-negra da bananeira. Brasília, Embrapa, 177 p.

Marcelino, L.A.; González, V.; Guerra, P. 2003. Evaluacción de práticas para la reducción del inóculo interno y su efecto dobre el control de la sigatoka-negra. In: Pocasangre, L.; Rosales, F.E.; Guzmán, M. (Eds.). Capacitacion e investigación para el manejo integrado de la sigatoka-negra del plátano en America Latina y el Caribe. Documento II. Informe final. San Jose, INIBAP. p.204 - 218 .

Orozco-Santos, M. 1998. Manejo integrado de la Sigatoka Negra del plátano. México, DF,INIFAP, 96pp. ( Folheto Técnico, 1).

Pereira, J.C.R.; Gasparotto, L.; Coelho, A.F.S.; Urben, A. 1998. Ocorrência da Sigatoka Negra no Brasil. Fitopatologia brasileira, 23 (Suplemento): 295.

Pérez, S.L. 1993. Densidades de población alta en plátano, "Curare" (Musa AAB). Turrialba, 19(42): 25-30.

Stover, R.H. 1987. Producción de plátano en presencia de la Sigatoka negra. UPEB, 11(82): 50-56.

Surga, J.C.; Gómez, C.; Rumbos, R.; Trujillo, V. 2003. Evaluacción de sistema de cultivos de plátanos en alta densidad, con un manejo integrado de la sigatoka-negra, promoviendo o uso racional de los fungicidas. In: Pocasangre, L.; Rosales, F.E.; Guzmán, M. (Eds.). Capacitacion e investigación para el manejo 
integrado de la sigatoka-negra del plátano en America Latina y el Caribe. Documento II. Informe final. San Jose, INIBAP,. p.268-280.

Vargas, M.; Castillo, J.G.S. 2003. Evaluacción de sistema de cultivos de plátanos en alta densidad, con un manejo integrado de la sigatoka-negra, promoviendo o uso racional de los fungicidas. In: Pocasangre, L.; Rosales, F.E.; Guzmán, M. (Eds.). Capacitacion e investigación para el manejo integrado de la sigatoka-negra del plátano en America Latina y el Caribe. Documento II. Informe final. San Jose, INIBAP. p.121-140.
Vargas, A. 1993. Validación de tecnologia de producción para alto rendimiento en el cultivo del plátano Curraré o Falso Cuerno (Musa AAB) en el Atlántico de Costa Rica. Corbana, 19(42): 17-24.

Vicente, L.P. 1998. Sigatoka negra (Mycosphaerella fijiensis Morelet) de bananas y plátanos (Musa ssp.) en Cuba. Biología, epidemiología y manejo integrado de la enfermedad. In: Simposium Internacional sobre Sigatoka Negra, 1998, 1. Manzanillo. Memorias... Manzanillo, SAGAR/INIBAP. p.24-52.

Recebido em 05/07/2006

Aceito em 01/02/2008 